\title{
Editorial Introduction: Residential Services for Children and Adolescents Impacted by Family Violence and Trauma
}

\author{
Andrew Pond • Joseph Spinazzola
}

Published online: 5 September 2013

(C) Springer Science+Business Media New York 2013

There are times when our experiences as clinicians, practitioners, and managers align in a moment of enlightenment. This happened for one of us (Pond) several months ago at a meeting of foster parents who have been trained to provide intensive support to particularly vulnerable youth. In my welcoming remarks, I reflected upon some of the challenges associated with working with children whose lives have been impacted by multiple and chronic or recurrent interpersonal trauma, violence and neglect, experiences often referred to collectively as "complex trauma" (see Cook et al. 2005; Spinazzola et al. 2005; Spinazzola et al. 2013). I noted that residential programs see the same population of traumatized youth - often sharing cases and transition plans. We know from consistent federal data that in excess of 100,000 U.S. children and adolescents newly enter out-of-home placements each year (U.S. Department of Health and Human Services 2012).

In some instances the determination of whether to place a maltreated child with a foster family versus within a congregate is based upon the acuity or severity of emotional and behavioral difficulties exhibited by these highly vulnerable youth. For example, through analysis of one of the world's largest child trauma databases, our colleagues at National Center for Child Traumatic Stress (NCCTS) have demonstrated that youth in residential treatment settings constitute the most vulnerable subgroup of children and adolescents victimized by trauma, exhibiting the highest rates of trauma exposure, associated impairment, and need for extensive intervention (Briggs et al. 2012). Just as often, however, out-of-home

\footnotetext{
A. Pond

Justice Resource Institute, Needham, MA, USA

J. Spinazzola $(\bowtie)$

The Trauma Center at Justice Resource Institute,

Brookline, MA, USA

e-mail: jspinazzola@jri.org
}

placement decisions are seemingly "the luck of the draw," predicated upon local resources and capacity, and in many instances ultimately decided by whoever happens to be next in line for an available bed.

Later during this meeting we had a guest speaker, Hector, a man now in his mid-thirties, who spoke about his life as one of these children who spent years in out-of-home placements. His story is all too common, although his level of insight about the impact of his experiences was exceptional. Hector approached me after the event, and told me that when I spoke about the impact of repeated, familial trauma-physical abuse, witnessing domestic violence, and chronic disruption of placements- "You are talking about me. That's my story." Sadly, this disclosure was hardly surprising considering recent research by our NCCTS colleagues establishing that over $70 \%$ of children in foster care have been exposed to complex trauma (see Greeson et al. 2011).

Through his entire childhood, Hector witnessed severe domestic violence and suffered frequent physical abuse. The violence escalated; his mother began to beat him to the point that he feared for his life. Even though he had barely turned 13 , Hector had the bravery to walk into a social services office and ask that he be put into a safe place. Hector thought this act would be his salvation - what he knew of foster families was from television, and he thought what he would find would be a family, or other caregivers that would help him and keep him safe. Instead, he experienced further disconnection and continuing loss. For the next 3 years, he was "bounced" from setting to setting, by his count nearly twenty (20) times. He went to nine different high schools. By his account, he was moved no matter how he behaved. In his mind, if he was good, that was progress, and he was moved on. If he was "bad" he was not making progress, and was moved on. He described himself at 15 as hopeless, and alienated, and angry.

Then, just as he turned 16, he met a family trained to provide more intensive support that demonstrated, through 
their actions and demeanor, that they valued him and that he was worthy of care and connection. As we know is common with abused children, his reaction to this support was not immediate progress. He tested the adults. When he ran away, they took him back. This commitment to success is something that we have learned that all out-of-home services for children must have. Commitment and connection may even trump cultural and ethnic differences - he was a Hispanic youth, yet the connection with the Anglo adults working with him was very real, and very deep. He began to make true progress with peers, other family members, and in school. He began to have hope about his prospects. Today, we might say that his specialized foster parents were "attuned" to his needs (see Hodgdon et al. 2013). Hector - despite all the abuse, neglect, abandonment, and failure he had experienced - found a way to orient toward success.

Even with these caring and connected adults in his corner, he did not experience a smooth transition to young adulthood. Hector admits that he had poor impulse control, and was hypervigilant, easily overwhelmed, and had limited capacity to accurately assess situations in which he felt at risk. At 17, an adult by state legal standards at the time, he was involved in a serious altercation at his high school. He was convicted, and found himself-looking even younger than his 17 years - an inmate in adult corrections. There was no treatment, no support, no understanding of his trauma history - it was possibly the worst place imaginable for a young person with his history and needs.

This might have been the end of the road for Hector. A family that abused him, a well-intentioned children's services agency unable to support him effectively, and a legal system stacked against a youth - treating him not as a teenaged victim of complex trauma, but instead as a hardened adult criminal. Very few of us would have seen much hope for Hector as he turned 18 in prison.

Yet his exceptionally committed adult caregivers, the ones he finally connected with, didn't give up on him. They visited him in prison. They gave material and emotional support. They helped convince him that all was not lost. They saw that he was still a resilient and potentially successful youth, not a criminal. They stayed with him. Hector believes that their tenacity in the face of his tough situation, as much as anything else, saved him from complete destruction. Obviously other factors may have been important. It seems likely, whether from innate or mitigating environmental factors, that Hector was more resilient than others might have been under similar circumstances. Hector was also - obviously to those who know him now-a highly intelligent young person, skilled in writing Spanish and English, even publishing poems while in high school. He had the capacity to self-reflect, and eventually to see a path out of misery. He had strengths, but it required attuned adults in his life to allow him the opportunity to benefit from his inherent strengths (see Kagan and Spinazzola 2013).
In the pages that follow, there are similar lessons for individuals, for clinicians, and for managers, as well as for systems, for provider agencies, and for state agencies. The clinician will benefit from descriptions of specific techniques for use with traumatized youth (see Brown et al. 2013; D'Andrea et al. 2013; Habib et al. 2013; Hodgdon et al. 2013; Kagan and Spinazzola 2013; Warner et al. 2013). Those of us who operate private agencies can learn to be responsive to the need to allow for connection to occur, creating a space for staff to feel confident and supported in their efforts to assist (see Hodgdon et al. 2013; Knoverek et al. 2013). Public agencies can continue to focus on permanency as a goal (see Spinazzola et al. 2013), while working to transform institutions that historically have viewed youth residing within their facilities from more pathologizing and at times even punitive mindsets into trauma-informed systems of care (see Ford and Blaustein 2013; Zelechoski et al. 2013). Even legislators can learn —and act upon - the fact that the developmental path of any child does not end at 18 (let alone 17) - those of us with teenaged children (or who were teenaged problem children) know that development continues well into the 20s; and for children like Hector, that process may take longer, and certainly will require more sophisticated supports (see Cook et al. 2005; Knoverek et al. 2013; Zelechoski et al. 2013).

Hector's story began more than two decades ago, and recent years have seen some real progress in the emphasis on measuring and minimizing placement disruption, a deleterious phenomenon that has been identified as a high risk trajectory for children with complex trauma in the child welfare system (see Kisiel et al. 2009). Our generation has witnessed great strides in the understanding of and strategic progress toward attainment of placement permanency for youth impacted by complex trauma (see, for example, Arvidson et al. 2011). As an integral element of these efforts, we have experienced the resurgence of family preservation initiatives on state and federal levels. As promising as many of these initiatives have demonstrated to be, we cannot overlook the stark reality that in our country, fully $97 \%$ of substantiated cases of child maltreatment continue to occur within the context of family violence (see, for example, Sedlak et al. 2010). Our understanding of the immense challenges and struggles experienced by many complexly traumatized children - and by the biological, kinship, foster or adoptive families that endeavor to care for them-to sustain in-home placements cannot be divorced from this context.

For many youth victims of family violence, "home," "family," and "adult affection," have become toxic constructs, and emotional reliance and dependency upon parental figures an untenable proposition. This is perhaps the most profound and at times enduring legacy of children's exposure to abuse, abandonment, betrayal and exploitation. Ironically, the more consistent structure and reduced intimacy of well-designed trauma-informed residential treatment settings can often 
provide a more optimal setting for such youth to be assisted by caring adults to build internal capacities the cultivation of which had been stunted by chronic neglect, and to reroute developmental trajectories that had been derailed by chronic exposure to threat and the ensuing maladaptive consequences of survival-based coping (Spinazzola et al. 2013).

The first section of this special issue examines these and other contextual issues surrounding residential treatment of children and adolescents impacted by complex trauma and family violence. Zelechoski et al. (2013) provide an overview of the small but growing body of literature on this topic and highlight key policy implications for the continuum of child service agencies that engage these youth and their caregivers. Ford and Blaustein (2013) closely examine the needs, challenges and misconceptions involved in recognizing and serving complexly traumatized youth in juvenile justice settings. Knoverek et al. (2013) explore avenues for understanding and intervention with the least studied subgroup of children in residential care: young children with histories of complex trauma.

The second section of this issue consists of papers featuring four child and adolescent complex trauma intervention models with emerging evidence-base supporting their use in residential treatment settings. Three of these papers describe more systemic, components-based approaches to complex trauma intervention in residential settings, using the Attachment, Regulation and Competency (ARC; Hodgdon et al. 2013), Real Life Heroes (RLH; Kagan and Spinazzola 2013); and Trauma Systems Therapy (TST; Brown et al. 2013) intervention models. A fourth paper features application in residential settings of a more focused, session-protocol based intervention for adolescents with complex trauma: Structured Psychotherapy for Adolescents Responding to Chronic Stress (SPARCS; Habib et al. 2013).

The third and final section of this special issue consists of two papers offering innovative approaches to and envisioning future directions for intervention with traumatized youth in residential treatment settings. Warner and colleagues explore applications of sensory motor, sensory integration and occupational therapy practices as a component of treatment with this population, and introduce a new model of sensory-based, trauma-focused intervention: Sensory Motor Arousal Regulation Therapy (SMART; Warner et al. 2013). D'Andrea et al. (2013) introduce a therapeutic sportsbased model of intervention with traumatized youth: Do the Good (DtG).

Concluding with where we began this introduction, we feel compelled to acknowledge that Hector did not escape from his experiences unscathed. He is still dogged by a criminal record from his altercation at 17, and has had other challenges in his community. But since his late teens, his record has remained clean. He has worked in a variety of jobs, including one as a school-parent program coordinator for inner city families. As we - in our multiple roles as managers, clinicians, and public policy advocates - discussed the lessons that Hector's story teaches us, we came to realize that while we are confident that we are doing a better job than we were 20,10 , or even 5 years ago, there is still much to learn. One lesson that we are taking to heart today is to become better at direct learning from those who have experienced complex trauma associated with family violence and placement disruption. Hector has accepted a specially-designed fellowship position at our agency, with several components. He is meeting with children in residential settings as a mentor and guide to getting the most benefit from their out-of-home placement. He is working with staff to help them understand the "kid's eye view" of their lives. And he is also beginning training with experts in trauma treatment, child development, and education, with an eye toward his own professional development. Our shared goal is to add another passionate, caring, and trained voice to our collective work.

The articles that follow offer a series of perspectives and approaches to helping childhood victims of complex trauma. Hector's story is a reminder of the tenacity and resilience of these children. While in Hector's case a single meaningful therapeutic connection played a significant role in his survival, in most instances that's not enough. We have to increase those odds. We have to make that success a routine part of our interventions. Our charge is to find-in every traumatized child - the best way to reach each one, and systematically to improve our work through ongoing research and continuously improving practice.

\section{References}

Arvidson, J., Kinniburgh, K., Howard, K., Spinazzola, J., Strothers, H., Evans, M., \& Blaustein, M. E. (2011). Treatment of complex trauma in young children: developmental and cultural considerations in applications of the ARC intervention model. Journal of Child and Adolescent Trauma, 4, 34-51.

Briggs, E. C., Greeson, J. K. P., Layne, C. M., Fairbank, J. A., Knoverek, A. M., \& Pynoos, R. S. (2012). Trauma exposure, psycholosocial functioning, and treatment needs of youth in residential care: preliminary findings from the NCTSN core data Set. Journal of Child and Adolescent Trauma, 5, 1-15.

Brown, A. D., McCauley, K., Navalta, C. P., \& Saxe, G. N. (2013, this issue). Trauma Systems Therapy in residential settings: Improving emotion regulation and the social environment of traumatized children and youth in congregate care. Journal of Family Violence, 28(7).

Cook, A., Spinazzola, J., Ford, J., Lanktree, C., Blaustein, M., Cloitre, M., \& van der Kolk, B. (2005). Complex trauma in children and adolescents. Psychiatric Annals, 35, 390-398.

D’Andrea, W., Bergholz, L., Fortunato, A., \& Spinazzola, J. (2013, this issue). Play to the whistle: A pilot investigation of a traumainformed sports-based intervention for girls in residential treatment. Journal of Family Violence, 28(7).

Ford, J.D., \& Blaustein, M.E. (2013, this issue). Systemic SelfRegulation: A Framework for Trauma-Informed Services in 
Residential Juvenile Justice Programs. Journal of Family Violence [CITATION]

Greeson, J. K. P., Briggs, E. C., Kisiel, C. L., Layne, C. M., Ake, G. S., Ko, S. J., \& Fairbank, J. A. (2011). Complex trauma and mental health in children and adolescents placed in foster care: findings from the National Child Traumatic Stress Network. Child Welfare, 90(6), 91-108.

Habib, M., Labruna, V., \& Newman, J. (2013, this issue). Complex Histories and Complex Presentations: Implementation of a Manually-Guided Group Treatment for Traumatized Adolescents. Journal of Family Violence, 28(7).

Hodgdon, H., Kinniburgh, K., Gabowitz, D., Blaustein, M., \& Spinazzola, J. (2013, this issue). Development and implementation of trauma-informed programming in residential schools using the ARC framework. Journal of Family Violence, 28(7).

Kagan, R., \& Spinazzola, J. (2013, this issue). Real Life Heroes in residential treatment: Implementation of an integrated model of trauma and resiliency-focused treatment for children and adolescents with complex PTSD. Journal of Family Violence, 28(7).

Kisiel, C. L., Fehrenbach, T., Small, L., \& Lyons, J. (2009). Assessment of complex trauma exposure, responses and service needs among children and adolescents in child welfare. Journal of Child and Adolescent Trauma, 2, 143-160.

Knoverek, A. M., Briggs, E. C., Underwood, L. A., \& Hartman, R. L. (2013, this issue). Clinical considerations for the treatment of latency age children in residential care. Journal of Family Violence, 28(7).
Sedlak, A. J., Mettenburg, J., Basena, M., Petta, I., McPherson, K., Greene, A., \& Li, S. (2010). Fourth national incidence study of child abuse and neglect (NIS-4): Report to congress. Washington, DC: U.S. Department of Health and Human Services, Administration for Children and Families.

Spinazzola, J., Ford, J. D., Zucker, M., van der Kolk, B. A., Silva, S., Smith, S. F., \& Blaustein, M. (2005). National survey evaluates complex trauma exposure, outcome, and intervention among children and adolescents. Psychiatric Annals, 35, 433-439.

Spinazzola, J., Habib, M., Knoverek, A., Arvidson, J., Nisenbaum, J., Wentworth, R., \& Kisiel, C. (2013). The heart of the matter: Complex trauma in child welfare. CW360 Trauma-Informed Child Welfare Practice - Winter 2013, CASCS, University of Minnesota, pp. 8-9, 37.

U.S. Department of Health and Human Services, Administration for Children and Families, Administration on Children, Youth and Families, Children's Bureau (2012). Child Maltreatment 2011. Available from http://www.acf.hhs.gov/programs/cb/research-datatechnology/statistics-research/child-maltreatment.

Warner, E., Koomar, J., Lary, B., \& Cook, A. (2013, this issue). Can the body change the score? Application of sensory modulation principles in the treatment of traumatized adolescents in residential settings. Journal of Family Violence, 28(7).

Zelechoski, A. D., Sharma, R., Beserra, K., Miguel, J., DeMarco, M., \& Spinazzola, J. (2013, this issue). Traumatized youth in residential treatment settings: Prevalence, clinical presentation, treatment, and policy implications. Journal of Family Violence, 28(7). 